\title{
PERUBAHAN SCORE BLEACHEDGUIDE DAN NILAI KEKERASAN ENAMEL GIGI SEBELUM DAN SESUDAH DILAKUKAN BLEACHING KARBAMID PEROKSIDA 35\%
}

\author{
(CHANGES IN BLEACHEDGUIDE SCORE AND HARDNESS VALUES OF \\ TOOTH ENAMEL BEFORE AND AFTER BLEACHING WITH 35\% \\ CARBAMIDE PEROXIDE)
}

Rehulina Ginting, Ashvinaa Morgan

Departemen Biologi Oral, Fakultas Kedokteran Gigi, Universitas Sumatera Utara Jl. Alumni No.2 Kampus USU Medan

\begin{abstract}
Bleaching is one of the esthetic treatments to whiten discoloured teeth. Besides whitening effects, bleaching also has negative effects towards teeth such as reducing the enamel hardness that is caused by the oxidation process of peroxide agents which reduces the $\mathrm{Ca}^{2+}$ and $\mathrm{PO}_{4}{ }^{3-}$ components in enamel. The purpose of this study is to determine the changes that occurs before and after bleaching with $35 \%$ carbamid peroxide, which are decrement in tooth shade scores according to VITA Bleachedguide 3D-Master, and decrement in hardness value (HV) of tooth enamel between before and after bleaching with $35 \%$ carbamid peroxide. This is an experimental research done with pre-post test design. This research was carried out on 20 discolored permanent maxillary first premolar which are cut into $5 \times 5 \times 4 \mathrm{~mm}$ speciments from the buccal surface then embedded in clear epoxy resin. The tooth shade scores of the speciments were measured with VITA Bleachedguide 3D-Master, and hardness values (HV) of tooth enamel measured with Vicker's Hardness Tester before and after bleaching with $35 \%$ carbamide peroxide an hour a day for seven consecutive days. The results showed that tooth shade score decreased by $1.60 \pm 0.60$ tabs according to VITA Bleachedguide 3D-Master between before and after bleaching was significant at $\mathrm{p}<0.05$. Hardness value of tooth (HV) decreased by $29,15 \pm 8,88 \mathrm{HV}$ between before and after bleaching which is significant at $\mathrm{p}<0.05$. In conclusion, bleaching with carbamide peroxide $35 \%$ can decrease tooth shade scores (whiter tooth), but at the same time has negative effects on tooth such as decreasing in enamel hardness.
\end{abstract}

Key words: Bleaching, Tooth shade score, Hardness value of tooth (HV)

\begin{abstract}
Abstrak
Bleaching merupakan salah satu perawatan estetik untuk memutihkan gigi yang mengalami diskolorisasi. Selain efek memutihkan gigi, bleaching memiliki efek negatif terhadap gigi yaitu menurunnya nilai kekerasan enamel akibat proses oksidasi bahan peroksida sehingga komponen $\mathrm{Ca}^{2+}$ dan $\mathrm{PO}_{4}^{3-}$ menjadi berkurang. Tujuan penelitian ini adalah untuk mengetahui perubahan yang terjadi antara sebelum dan sesudah perlakuan bleaching karbamid peroksida 35\% yaitu terdapat penurunan skor warna berdasarkan VITA Bleachedguide 3D-Master dan penurunan nilai kekerasan (HV) enamel gigi. Jenis penelitian ini adalah eksperimental murni dengan rancangan penelitian pre-post test design. Penelitian ini dilakukan pada 20 spesimen premolar pertama maksila permanen yang telah mengalami diskolorisasi dan dipotong bagian bukal gigi sehingga menghasilkan spesimen berukuran 5 x 5 x $4 \mathrm{~mm}$ kemudian ditanam dalam resin epoksi. Skor warna spesimen gigi diukur dengan menggunakan Bleachedguide, dan nilai kekerasan enamel gigi (HV) dengan alat penguji kekerasan Vicker's sebelum dan sesudah perlakuan bleaching karbamid peroksida 35\% satu jam sehari selama tujuh hari berturut-turut. Hasil penelitian menunjukkan terdapat penurunan yang signifikan pada skor warna sebanyak 1,60 \pm 0,60 tingkat antara sebelum dibanding sesudah bleaching pada $\mathrm{p}<0,05$ dengan VITA Bleachedguide 3D-Master. Nilai kekerasan (HV) mengalami penurunan yang signifikan sebanyak 29,15 $\pm 8,88 \mathrm{HV}$ antara sebelum dibanding sesudah bleaching pada $\mathrm{p}<0,05$. Sebagai kesimpulan, tindakan pemutihan gigi (bleaching) dengan karbamid peroksida $35 \%$ ternyata dapat menurunkan skor warna gigi (warna gigi bertambah putih), tetapi pada waktu yang sama mempunyai dampak negatif terhadap gigi yaitu penurunan nilai kekerasan enamel.
\end{abstract}

Kata kunci: Bleaching, Skor warna gigi, Nilai kekerasan gigi (HV) 


\section{PENDAHULUAN}

Penampilan gigi merupakan salah satu aspek yang penting dalam menentukan keindahan senyum seseorang, dimana sebuah senyuman yang memperlihatkan gigi yang putih, bersih dan sehat dapat meningkatkan percaya diri seseorang untuk berkomunikasi dengan orang lain. Saat ini, permintaan terhadap perawatan pemutihan gigi semakin meningkat. Menurut TinOo MM et al. sebanyak 56,2\% dari 235 subjek yang diteliti berasa tidak puas terhadap warna giginya.

Gigi permanen yang normal adalah berwarna putih keabu-abuan atau putih kekuningan. Warna gigi dapat dipengaruhi oleh transluensi dan ketebalan enamel, serta ketebalan dan warna dentin yang ada dibawahnya. Warna gigi dapat berubah akibat faktor intrinsik (pewarnaan endogen yang terjadi di bagian dalam struktur gigi) atau faktor ekstrinsik (perubahan warna gigi yang terjadi pada permukaan luar enamel gigi). ${ }^{2}$

Seiring dengan perkembangan ilmu kedokteran gigi yang mengarah kepada pendekatan invasif minimal, bleaching sering dipilih oleh dokter gigi karena prosedurnya bersifat konservatif. ${ }^{3}$ Bahan yang sering dipakai pada perawatan bleaching adalah hidrogen peroksida dan karbamid peroksida (oksidator kuat). Menurut American Dental Association (ADA) karbamid peroksida lebih sering digunakan dalam perawatan pemutihan gigi karena efektivitas peningkatan kecerahan bahan ini lebih baik serta lebih aman bila dibandingkan dengan hidrogen peroksida. ${ }^{3,4}$ Mekanisme reaksi pemutihan gigi masih belum diketahui secara pasti, namun diduga radikal bebas yang dihasilkan saat proses oksidasi akan memecahkan molekul pigmen kromofor menjadi molekul yang kecil yang tidak mampu memantulkan cahaya yang banyak, sehingga menyebabkan gigi kelihatan lebih cerah dan warna gigi menjadi lebih putih. ${ }^{5}$ Metode penilaian pemutihan pada gigi dapat dilakukan antara lain dengan shade guide. ${ }^{6}$

Sifat oksidasi bahan karbamid peroksida dapat menimbulkan efek samping yaitu pelepasan ion kalsium dan fosfor, perubahan morfologi permukaan enamel, dan penurunan kekerasan enamel. Proses oksidasi bahan peroksida akan menyebabkan pelepasan ion-ion kalsium dan fosfat sehingga molekul hidroksiapatit menjadi lemah dan tidak stabil dan mengakibatkan struktur enamel menjadi poreus dengan pola honey-comb. Perubahan ini dapat mengurangi kekerasan enamel. $^{7}$

Penelitian untuk mengevaluasi efek pemutihan gigi pada beberapa jenis bahan bleaching dan efek sampingnya pada enamel penting dilakukan untuk memberikan informasi kepada dokter gigi dalam hal pemilihan bahan bleaching yang tepat untuk pasien.
Dari aspek klinis, dokter gigi sebaiknya memilih bahan bleaching yang menghasilkan efek pemutihan gigi dan nilai kecerahan gigi yang maksimal sementara mempunyai efek samping terhadap jaringan keras gigi yang seminimal mungkin. Delfino CS et al. (2009) telah melakukan penelitian untuk mengevaluasi efek beberapa bahan home bleaching (karbamid peroksida $10 \%$, karbamid peroksida $16 \%$, dan hidrogen peroksida 6.5\%) terhadap warna gigi dan kekerasan enamel. Hasilnya, didapati bahwa karbamid peroksida $16 \%$ merupakan bahan yang paling efektif dari segi pemutihan gigi dan penurunan kekerasan enamel $\Delta K H N$ yang paling sedikit yaitu sebanyak $6.58{ }^{4}$

Berdasarkan uraian di atas, maka penulis tertarik untuk melakukan penelitian untuk mengetahui score warna gigi berdasarkan VITA Bleachedguide 3DMaster dan kekerasan enamel gigi sebelum dan sesudah dilakukan bleaching dengan bahan bleaching yang berkonsentrasi tinggi yaitu karbamid peroksida $35 \%$.

\section{BAHAN DAN METODE}

Penelitian ini merupakan penelitian eksperimental murni dengan rancangan pre-post test design. Sampel pada penelitian ini adalah 20 gigi premolar pertama maksila permanen yang telah diekstraksi untuk kepentingan ortodonti. Sampel diambil secara purposive sampling sesuai kriteria inklusi yaitu berwarna $1 \mathrm{M} 2,1.5 \mathrm{M} 2,2 \mathrm{M} 2,2.5 \mathrm{M} 2,3 \mathrm{M} 2,3.5 \mathrm{M} 2,4 \mathrm{M} 2$, 4.5M2, 5M2, 5M2.5, dan 5M3 berdasarkan VITA Bleachedguide 3D-Master, dan berasal dari pasien laki-laki dan perempuan yang berusia 16 hingga 25 tahun, sementara kriteria eksklusi sampel penelitian adalah gigi tambalan, karies, crown, gigi yang pernah dilakukan perawatan saluran akar, bleaching, dan ortodonti, gigi patologis seperti fraktur, abrasi dan atrisi, serta anomali gigi seperti amelogenesis imperfekta dan dentinogenesis imperfekta.

Sampel gigi yang telah dikumpul direndam dalam larutan $\mathrm{NaCl}$ 0,9\% untuk mensterilkan dan membuat gigi tetap dalam keadaan fisiologis setelah pencabutan serta mencegah dehidrasi. Spesimen gigi yang berukuran $5 \times 5 \times 4 \mathrm{~mm}$ diambil dari permukaan bukal dengan memotong sampel gigi pada sisi mesial, distal, oklusal, dan servikal menggunakan bur disk. Kemudian spesimen ditanam ke dalam resin epoksi dengan perbandingan resin dan katalis 1:1 dalam tabung spuit dan hanya permukaan bukal sampel tidak tertutup oleh resin karena merupakan permukaan yang akan dilakukan bleaching. Setelah itu permukaan bukal sampel dipolis dengan kertas abrasif 600 dan 1200 grit untuk mendapatkan permukaan yang rata untuk pengujian kekerasan dengan Vicker's Hardness Tester. Pengukuran skor warna gigi se- 
belum bleaching dilakukan dengan VITA Blachedguide $3 D$-Master dimana setiap tingkat warna diberi score berdasarkan urutannya pada shade guide (Gambar 1). Warna gigi dievaluasi di bawah cahaya matahari dengan berlatarbelakangkan kertas hitam. Observasi warna gigi dilakukan oleh tiga pengamat. Apabila dua atau lebih pengamat mendapat hasil yang sama, maka warna tersebut dicatat. Nilai kekerasan (HV) diukur dengan menggunakan Vicker's Hardness Tester (Future-tech FM-800) (Gambar 2). Spesimen diberi beban $200 \mathrm{~g}$ selama 15 detik dan 3 indentasi dibuat pada permukaan bukal spesimen kemudian rerata nilai kekerasan (HV) untuk setiap spesimen dihitung.

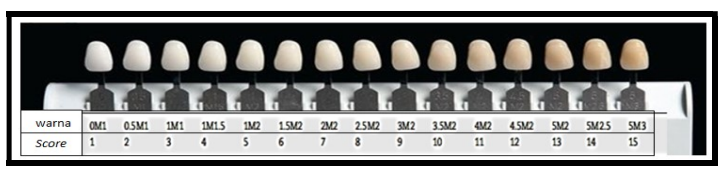

Gambar 1. Score warna gigi berdasarkan urutan tingkat warna pada VITA Bleachedguide 3D-Master

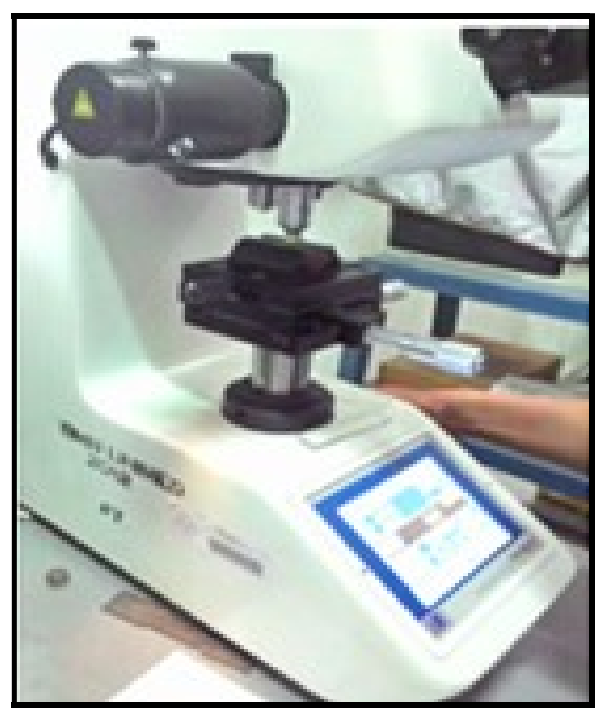

Gambar 2. Vicker's hardness tester

Setelah itu, semua spesimen gigi diberi perlakuan bleaching dengan karbamid peroksida 35\% (DENJOY,
China) sebanyak $0,1 \mathrm{ml}$ untuk satu jam sehari selama tujuh hari berturut-turut sesuai instruksi pabrik. Pengukuran skor warna dan nilai kekerasan (HV) dilakukan kembali setelah bleaching. Data mengenai skor warna dan nilai kekerasan (HV) sebelum dan sesudah bleaching dianalisa secara statistik dengan menggunakan uji $\mathrm{T}$ berpasangan untuk mengetahui signifikansi perubahan skor warna dan nilai kekerasan antara sebelum dan sesudah bleaching.

\section{HASIL}

Tabel 1 menunjukkan dari 20 sampel gigi yang diperoleh, rerata penurunan score warna adalah sebanyak $1,60 \pm 0,60$, sementara rerata penurunan nilai kekerasan $(\Delta \mathrm{HV})$ adalah sebanyak $29,15 \pm 8,88$. Analisa uji $\mathrm{T}$ berpasangan menunjukkan terdapat penurunan tingkat warna dan nilai kekerasan yang signifikan pada semua sampel penelitian setelah diberi perlakuan bleaching dengan karbamid peroksida 35\% $(\mathrm{p}<0,05)$.

\section{PEMBAHASAN}

Bleaching merupakan suatu perawatan estetik yang semakin populer dalam kalangan masyarakat saat ini menurut survei yang dilakukan oleh Akarslan et al. Hal ini mungkin disebabkan oleh pemahaman mereka bahwa bleaching merupakan suatu prosedur untuk merestorasi estetik gigi yang tidak rumit dan tidak sakit. ${ }^{8}$ Keberhasilan perawatan bleaching dapat diukur dengan shade guide. ${ }^{6}$ Pada penelitian ini, tingkat putihnya gigi diukur dengan VITA Bleachedguide 3D-Master karena shade guide ini didesain khusus untuk mengevaluasi warna gigi sebelum dan sesudah dilakukan bleaching, yang mana shade guide ini mempunyai cakupan warna yang lebih baik dan mengutamakan parameter kecerahan atau value dibanding VITA Classical shade guide yang sering digunakan oleh dokter gigi. ${ }^{9}$ Skor warna yang semakin rendah menunjukkan warna gigi yang semakin putih, sementara semakin tinggi skor warna menunjukkan warna ggi yang semakin gelap.

Tabel 1. Rata-rata penurunan score warna sampel dan penurunan nilai kekerasan sampel (HV) antara sebelum dan sesudah perlakuan bleaching dengan karbamid peroksida 35\%

\begin{tabular}{|c|c|c|c|c|c|c|c|c|c|}
\hline \multirow{2}{*}{ Kelompok } & \multirow{2}{*}{$\mathrm{N}$} & \multicolumn{3}{|c|}{ Sebelum bleaching } & \multicolumn{3}{|c|}{ Sesudah bleaching } & \multirow{2}{*}{$\begin{array}{l}\text { Selisih } \\
(\overline{\mathrm{x}} \pm \mathrm{SD})\end{array}$} & \multirow{2}{*}{$\operatorname{Sig}(p)$} \\
\hline & & Min. & Maks. & $(\overline{\mathrm{x}} \pm \mathrm{SD})$ & Min. & Maks & $(\overline{\mathrm{x}} \pm \mathrm{SD})$ & & \\
\hline Score warn & 20 & $\begin{array}{c}5 \\
(1 \mathrm{M} 2)\end{array}$ & $\begin{array}{c}13 \\
(5 \mathrm{M} 2)\end{array}$ & $\begin{array}{c}8,50 \pm \\
2,04\end{array}$ & $\begin{array}{c}4 \\
(1 \mathrm{M} 1.5)\end{array}$ & $\begin{array}{c}11 \\
(4 \mathrm{M} 2)\end{array}$ & $\begin{array}{c}6,09 \pm \\
2,17\end{array}$ & $\begin{array}{l}\text { (penurunan) } \\
1,60 \pm 0,60\end{array}$ & $0,0001^{*}$ \\
\hline $\begin{array}{l}\text { Nilai kekerasan sampel } \\
\text { (HV) }\end{array}$ & 20 & 245.8 & 344.6 & $\begin{array}{c}285,63 \pm \\
33,85\end{array}$ & 225.2 & 313.6 & $\begin{array}{c}255,93 \pm \\
33,70\end{array}$ & $\begin{array}{l}\text { (penurunan) } \\
29,15 \pm 8,88\end{array}$ & $0,0001^{*}$ \\
\hline
\end{tabular}

Uji T berpasangan, *signifikan $\mathrm{p}<0,05$ 
Pada penelitian ini, terdapat penurunan score warna yang signifikan sebanyak 1,60 $\pm 0,60$ tingkat antara sebelum dan sesudah perawatan bleaching karbamid peroksida $35 \%$ untuk satu jam sehari selama tujuh hari berturut-turut (Tabel 1). Hal ini berarti warna sampel gigi telah bertambah putih sesudah perlakuan bleaching. Penurunan skor warna gigi dapat terjadi sesudah perawatan bleaching karena radikal bebas yang dihasilkan oleh hidrogen peroksida akan memecahkan molekul kromofor menjadi fragmen kecil yang tidak dapat memantulkan cahaya yang banyak sehingga gigi kelihatan lebih putih dibanding warna gigi sebelum bleaching. ${ }^{5} \mathrm{Pe}-$ nurunan score warna gigi sesudah perlakuan bleaching dapat dipengaruhi oleh beberapa faktor, antara lain jenis bahan bleaching, konsentrasi dan lamanya aplikasi bleaching, keparahan diskolorisasi gigi, dan penggunaan katalis tambahan seperti sinar LED. Penelitian Ontiveros et al. mendapatkan penurunan score warna yang lebih banyak dibanding penelitian ini yaitu sebanyak $2,80 \pm 1,50$ sesudah perlakuan bleaching dengan bahan hidrogen peroksida $25 \%$ selama 45 menit untuk dua sesi bleaching. Perbedaan ini mungkin disebabkan oleh bedanya bahan bleaching yang digunakan yaitu karbamid peroksida $35 \%$ pada penelitian ini dan hidrogen peroksida $25 \%$ pada penelitian Ontiveros et al. ${ }^{9}$ Hasil penelitian ini juga mendapat penurunan score warna yang lebih sedikit dibanding penelitian Da Costa et al. yang mendapatkan jumlah penurunan score warna sebanyak 3,00 \pm 1,50 sesudah bleaching dengan karbamid peroksida $35 \%$. Perbedaan ini dapat terjadi karena bedanya frekuensi pengaplikasian bahan bleaching. Pada penelitian Da Costa et al. karbamid peroksida diaplikasi sejam sehari selama dua minggu, sementara pada penelitian ini karbamid peroksida hanya diaplikasi selama seminggu. ${ }^{10}$

Walaupun perawatan bleaching dapat memutihkan warna gigi dan meningkatkan kecerahan gigi secara efektif, tindakan bleaching juga dapat mengurangi nilai kekerasan enamel karena proses oksidasi bahan peroksida dapat menyebabkan pelepasan ionion kalsium dan fosfat. Kehilangan kandungan mineral ini dapat mengakibatkan prisma enamel menjadi poreus atau kelihatan seperti pola honey-comb secara mikroskopis sehingga menyebabkan kekerasan enamel berkurang. ${ }^{7}$

Pengujian kekerasan yang sering digunakan dalam penentuan kekerasan gigi adalah metode Knoop (KHN) dan metode Vickers (HV). Pada penelitian ini, pengujian kekerasan Vickers digunakan karena bentuk persegi yang dihasilkan oleh indentor Vickers lebih mudah diukur dan hasil juga lebih akurat, sementara lekukan yang dihasilkan oleh indentor Knoop berbentuk rhomboid sehingga pendeteksian kesalahan sulit dilakukan. Menurut Hora et al. ratarata nilai kekerasan enamel berkisar dari 250 hingga $360 \mathrm{HV} .{ }^{11}$ Pada penelitian ini, rerata spesimen sebelum perlakuan bleaching mempunyai nilai kekerasan yang berada dalam batas standar, yaitu $285,63 \mathrm{HV}$.

Hasil dari penelitian ini menunjukkan bahwa terdapat penurunan nilai kekerasan secara signifikan yaitu sebanyak 29,15 $\pm 8,88 \mathrm{HV}$ antara sebelum dan sesudah perlakuan bleaching untuk satu jam sehari selama tujuh hari berturut-turut (Tabel 1). Penelitian Hora et al. mendapat penurunan nilai kekerasan yang lebih sedikit dibanding penelitian ini, yaitu sebanyak 24,27 \pm 7,28 HV setelah dua aplikasi bleaching dengan McInnes bleaching agent (hidrogen peroksida 30\%) selama lima menit. ${ }^{11}$ Hasil penelitian ini dengan penelitian Hora et al. dapat disebabkan oleh bedanya bahan bleaching yang digunakan, yaitu pada penelitian ini karbamid peroksida 35\% digunakan. Karbamid peroksida mempunyai efek terhadap penurunan kekerasan enamel yang lebih sedikit dibanding hidrogen peroksida pada konsentrasi yang sama. Hal ini dapat disebabkan oleh kandungan kedua bahan peroksida ini, dimana karbamid peroksida 35\% mengandung bahan aktif hidrogen peroksida $12 \%$ dan urea $23 \%$ sebagai penetralisir sehingga proses oksidasi bahan ini lebih lambat dan aman, sementara hidrogen peroksida merupakan bahan peroksida murni. ${ }^{12}$ Selain itu, frekuensi dan lamanya aplikasi bahan bleaching pada penelitian Hora et al. lebih sedikit dibanding penelitian ini. ${ }^{11}$ Walaupun secara teori penggunaan hidrogen peroksida dapat menyebabkan penurunan nilai kekerasan yang lebih banyak dibanding karbamid peroksida, nilai kekerasan pada penelitian Hora et al. mengalami penurunan yang lebih sedikit dibanding penelitian ini karena sampel penelitian Hora et al. direndam dalam saliva buatan selama penelitian sementara pada penelitian ini larutan $\mathrm{NaCl}$ 0,9\% digunakan sebagai media penyimpanan sampel karena peneliti ingin mengetahui efek langsung bahan karbamid peroksida $35 \%$ terhadap kekerasan enamel gigi. Saliva mengandung ion kalsium dan fosfat yang akan memenuhi pori-pori prisma enamel dengan menggantikan mineral yang hilang sewaktu proses bleaching.

Walaupun remineralisasi dapat terjadi di dalam rongga mulut secara alami, prosedur remineralisasi gigi tambahan masih dilakukan oleh dokter gigi setelah selesai proses bleaching untuk mencegah kerusakan enamel akibat demineralisasi oleh bahan bleaching. Pelbagai bahan digunakan untuk meremineralisasi kembali enamel gigi, antaranya adalah pasta CPP-ACP, fluor, dan susu dimana bahanbahan ini mengandung kadar ion kalsium dan fosfor yang tinggi. ${ }^{4,13}$ 
Pada penelitian ini, dapat disimpulkan bahwa tindakan pemutihan gigi (bleaching) dengan karbamid peroksida $35 \%$, ternyata dapat menurunkan skor warna gigi (warna gigi bertambah putih), tetapi pada waktu yang sama mempunyai dampak negatif terhadap gig yaitu penurunan nilai kekerasan enamel.

\section{Daftar Pustaka}

1. Tin-Oo MM, Saddki N, Hassan N. Factors influencing patient satisfaction withdental appearance and treatments they desireto improve aesthetics. BMC Oral Health 2011; 11(6): 806-13.

2. Halim HS. Perawatan diskolorisasi gigi dengan teknik bleaching. Jakarta: Penerbit Universitas Trisakti, 2006: 5-20.

3. Lima FG, Rotta TA, Penso S, Meireles SS, Demarco FF. In vitro evaluation of the whitening effect of mouth rinses containing hydrogen peroxide. Braz Oral Res 2012; 26(3): 269-74.

4. Delfino CS, Chinelatti MA, Carrasco-Guerisoli LD, Batista AR, Froner IC, Palma-Dibb RG. Effectiveness of home bleaching agents in discoloured teeth and influence on enamel microhardness. J Appl Oral Sci 2009; 17(4): 284-8.

5. Li Y, Greenwall L. Safety issues of tooth whitening using peroxide-based materials. Br Dent J 2013; 215(1): 29-34.

6. Chu SJ, Trushkowsky RD, Paravina RD. Dental color matching instruments and systems. Review of clinical and research aspects. J Dent 2010; 38s: e2e16.

7. Rodrigues JA, Erhardt MCG, Marchi GM, Pimenta LAF, Ambrosano GMB. Association effect of inoffice and nightguard vital bleaching on dental enamel microhardness. Braz J Oral Sci 2003; 2(7): 365-9.

8. Akarslan ZZ, Sadik B, Erten H, Kaeabulut E. Dental esthetic satisfaction, received and desired dental treatments for improvement of esthetics. Indian $\mathrm{J}$ Dent Res 2009; 20(2): 195-200.

9. Ontiveros JC, Paravina RD. Color change of vital teeth exposed to bleaching performed with and without supplementary light. J Dent 2009; 1454: 1-8.

10. Da Costa JB, McPharlin R, Hilton T, Ferracane JL, Wang M. Comparison of two at-home whitening products of similar peroxide concentration and different delivery methods. Operative Dent 2012; 37(4): 333-9.

11. Hora B, Kumar A, Bansal R, Bansal M, Khosla T, Garg A. Influence of McInnes bleaching agent on hardness of enamel and the effect of remineralizing gel GC tooth mousse on bleached enamel: an invitro study. Indian J Dent Sci 2012; 2(4): 13-6.

12. Joiner A. Review of the effects of peroxide on enamel and dentine properties. J Dent 2007; 35: 889-96.

13. Davari AR, Danesh KAR, Ataei E, Vatanpour M, Abdollahi $\mathrm{H}$. Effects of bleaching and remineralising agents on the surface hardness of enamel. J Dent Shiraz Univ Med Scien 2012; 13(4): 156-63. 